Психология. Журнал Высшей школы экономики,

2020. T. 17. № 4. C. 779-790. DOI: 10.17323/1813-8918-2020-4-779-790

\title{
ХАРАКТЕРИСТИКИ НАРРАТИВОВ ДЕТЕЙ С РАЗНЫМ УРОВНЕМ ПОНИМАНИЯ ПСИХИЧЕСКИХ СОСТОЯНИЙ
}

\author{
А.Ю. УЛАНОВА \\ ${ }^{a}$ ФГБУН «Институт психологии РАН», 129366, Москва, ул. Ярославскал, д. 13, к. 1
}

\begin{abstract}
Резюме
Статья посвящена описанию результатов исследования различных компонентов нарративной компетенции детей 4 и 6 лет в контексте развития модели психического - системы репрезентации знаний о психических феноменах других людей. Нарратив рассматривается не только как важный коммуникативный инструмент и интегративная языковая способность, но и метод, позволяющий подойти к анализу понимания ментальных состояний и событий. Анализ структурных и содержательных характеристик детских повествований в соотношении с пониманием различных аспектов психического мира делает возможным изучение прагматических аспектов коммуникации: направленности на собеседника и способности принять в расчет его точку зрения. В исследовании приняли участие 60 детей, которые рассказывали истории партнеру - другому ребенку, неосведомленному слушателю. Нарративы детей, полученные по инструкции с пропущенным центральным эпизодом, оценивались по структуре, информативности, количеству и специфике описаний психических состояний. Оценка модели психического проводилась с помощью батареи задач, направленных на изучение различных аспектов психического мира - ложных убеждений, намерений, эмоций и др. Результаты показали скачок в развитии модели психического и нарративных способностей в период от 4 до 6 лет, а также изменение характера взаимосвязей между ними в выделенный возрастной период. Обнаружены различия по всем исследуемым характеристикам нарративов у детей с разным уровнем модели психического: дети с высоким уровнем более развернуто и последовательно описывали события, включая психические состояния героев и указание на их причинность. Показана возрастная специфика в описании психических состояний. Приведенные данные позволяют рассматривать модель психического как один из когнитивных ресурсов для конструирования нарратива.
\end{abstract}

Ключевые слова: нарратив, понимание психических состояний, модель психического, дошкольный возраст.

Проблема понимания психологической сущности себя и другого является чрезвычайно актуальной, так как имеет прогностическую силу в определении множества компетенций ребенка, связанных с его становлением как субъекта общения. Одним из современных подходов к изучению понимания психического мира является «модель психического» (Theory of mind), т.е. система репрезентаций психического, интенсивно развивающаяся в дошкольном возрасте и позволяющая объяснять причинность психических событий (Flavell,

Исследование выполнено при поддержке гранта Президента РФ МК-528.2017.6. 
2004; Сергиенко и др., 2009). Ключевой cпособностью и показателем развития модели психического многие авторы считают понимание неверных мнений (false beliefs), предполагающее разделение собственных психических состояний и состоянй партнера.

На сегодняшний день активно разрабатывается направление исследований, описывающее взаимооусловленное развитие модели психичекого и языка (Тompkins et al., 2019). Экспериментально показана связь между различными аспектами языкового развития и пониманием неверных мненй, в том числе синтаксических и семантически показателей речи (Astington, Jenkins, 1999). Результаты исследований, накопленные на данном этапе, не позволяют говорить о том, что общее речевое развитие и коммуникативный опыт определяют становление модели психического (Astington, Baird, 2005). Скорее авторы отмечают, что языковая способность развивается постепенно вместе с пониманием психичесого мира, поддерживая его, и в то же время наличие модели психического обеспечивает понимание собеседника и успешность коммуникации. Выделенная взаимообусловленность просматривается также при изучении атипичного развития: показатели модели психичекого отличаются у типично развивающихся детей и детей с нарушениями речи (Nilsson, de Lopez, 2016; Виленская, Лебедева, 2018).

В работах зарубежных авторов подчеркивается важность модели психичес кого для понимания повествования и разделения двух уровней сюжета: действия и сознания (Astington, 1990; Pelletier, Astington, 2004). Постулируется, что метакогнитивный язык (mental state language) позволяет детям понять убеждения и намерения персонажей историй, а на более высоких уровнях развития интерпретировать событие с точки зрения героя (O’Neill, Shultis, 2007). Исследования, посвященные использованию ментального словаря, демонстрируют противоречивые данные: с одной стороны, показано отсутстие взаимосвязи между показателями модели психического и ипотреблением слов, обозначающих психические состояния, с другой - наличие связи этих показателей с осуществлением референции в повествовании и пониманием ментальных слов (Charman, Shmueli-Goetz, 1998; Symons et al., 2005; Meins et al., 2006; и др.). При изучении нарративных способностей детей с РАС, традиционно испытывающих дефицит модели психического, описаны некоторые характеристики их высказываний: отсутстие направленности на слушателя и учета его потребностей, редкое указание причин происшедших событий описание психическх состояний персонажей, короткий и схематичный рассказ (Capps et al., 2000; Baixauli et al., 2016; и др.).

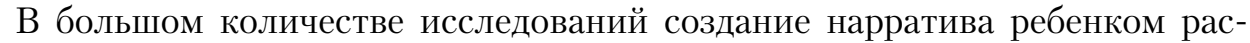
сматривается как способ передачи информации о психичеких явлениях в разговорах с родителями, сверстниками и т.д. Сами по себе нарративные спов соности в сооношении развитием модели психичесого изучены в первую очередь у школьников и в меньшей степени у детей дошкольного возраста, особенно детей до 5 лет. Методология подобных исследований отличается использованием широкого диапазона способов оценки, таких как анализ предложений, формирование умозаключений на основе услышанного, пересказ 
историй, упорядочивание изображений и пр. Материалом для анализа служат, как правило, истории, включающие описание неверного мнения или обмана, когда один персонаж обладает искаженной картиной реальности. Фокус более ранних исследований был направлен на оценку понимания причинно-следственных связей и способности детей воспроизводить цепочку и последовательность действий, выделять начало и результат событий (например: van den Broek et al., 1996). Позднее исследователи сосредоточились на изучении понимания сознания героев, выраженного в нарративах (Riggio, Cassidy, 2009; Pelletier, Beatty, 2015).

Дизайн настоящего исследования разрабатывался с опорой на имеющиеся данные с целью проведения разносторонней оценки детского повествования в контексте развития понимания психического мира. Анализ понимания событий в целом, а не части, основанной на неверном мнении, учет структурных и содержательных характеристик нарративов представляет актуальную исследовательскую задачу, не реализованную ранее на общей выборке детей среднего и старшего дошкольного возраста. Кроме того, в исследовании учитывается ограничение большинства западных работ в русле модели психического - производилась оценка только ключевого аспекта (понимания неверного мнения) в отрыве от других ее компонентов.

Цель настоящей работы - изучение возрастной специфики в развитии нарративной компетенции у детей 4-6 лет в контексте становления способности к пониманию психического мира. В качестве показателей нарративной компетенции выделены следующие характеристики - информативность, структура рассказа, описание психических состояний. Согласно нашему предположению, сопряженность между показателями нарративной компетенции и пониманием психического мира будет меняться с возрастом, а нарративы детей с более высоким уровнем модели психического будут отличаться большей развернутостью по выделенным характеристикам.

\section{Методы и участники исследования}

Участники. В исследовании приняли участие 60 детей из общеразвивающих групп детских садов г. Москвы, среди них 30 детей 4 лет $(\mathrm{Me}=4.2)$ и 30 детей 6 лет $(\mathrm{Me}=6.3)$. Группы были уравнены по полу. Участники проходили индивидуальное тестирование в отдельном помещении детского сада.

Методики. На начальном этапе для исключения влияния фактора интеллектуальной недостаточности была проведена оценка интеллектуального развития участников с помощью методик «Нарисуй человека» (Демидова и др., 1992) для детей 4 лет и «Цветные прогрессивные матрицы Равена» (Филимоненко, Тимофеев, 1994) для детей 6 лет. В выборку вошли дети, чьи результаты были выше минимального значения, относящегося к норме. Старшая возрастная группа также была исследована с помощью вербальных субтестов методики Д. Векслера (субтесты «Словарный» и «Сходство»), дающих первичное представление о речевом развитии участников. 
Для оценки развития модели психического были использованы классические парадигмальные задачи на понимание неверного мнения: задача «Sally\&Ann» (Wimmer, Perner, 1983) и «Неожиданное содержимое» (Gopnik, Astington, 1988). Понимание неверного мнения считается ключевой способностью в процессе становления модели психического, однако ею не ограничивается. Для более комплексной оценки также были использованы методические задачи, разработанные сотрудниками Института психологии РАН, направленные на оценку понимания других аспектов психического мира: «Распознавание эмоций по лицевой экспрессии на фотографиях», «Понимание намерений», «Понимание отличий причин движения физических и социальных объектов» (Лебедева, 2006), «Понимание ментальной и физической причинности событий», «Понимание юмора» (Уланова, Сергиенко, 2015). Коэффициент внутренней согласованности $(\alpha$ Кронбаха $=0.716)$ позволил использовать суммарный балл по семи задачам в качестве общего показателя модели психического. Для разделения выборки на подгруппы с низким, средним и высоким уровнем модели психического был использован метод деления на квартили внутри возрастных групп.

Для оценки нарративных способностей была разработана задача, в ходе которой каждый участник рассказывал историю неосведомленному слушателю - другому ребенку. Предварительно с опорой на иллюстрации рассказчику предъявлялась инструкция, состоящая из описания начала и исхода события (например, начало: «Мальчик пришел ловить рыбу, поставил ведро на землю. Рядом сидел кот»; исход: «Рыба пропала»). Центральный эпизод события был опущен с целью стимуляции речи ребенка, это позволяло анализировать авторский вклад при презентации события другому. Описание, выполненное ребенком, записывалось на диктофон, после чего в текстовом формате подлежало кодировке и анализу. Для анализа были выделены следующие критерии.

1. Информативность. Данный показатель оценивал содержательную полноту нарратива, предполагающую связность и целостность текста. Были выделены следующие уровни: информация передана недостаточно (путанный непоследовательный пересказ, отсутствие основных сюжетных элементов или замена события вымышленным); информация передана частично (нарушение причинно-следственной связи события, пропуск отдельных элементов сюжета); информация передана полностью, фактологически (пересказ содержал все основные смысловые сюжетные звенья в правильной последовательности); информация передана полностью с указанием ментальной причинности (правильная сюжетная последовательность с указанием ментального плана персонажей истории).

2. Структура рассказа. Критерий оценки из «Теста на определение нарративных навыков» (Gagarina et al., 2012). Учитывалось количество элементов, составляющих сюжет истории: введение (определение времени и/или места; например: «Жил на свете мальчик»), психическое состояние как начало события (например: «Кот захотел поесть рыбы»), цель (например: «Пошел мальчик на рыбалку»), попытка достижения цели («Кот понюхал, подошел к ведру 
и чуть-чуть толкнул»), результат ( Кот (ъел всю рыбу»), психическое состоя-

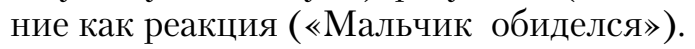

В Описание психичекого состояния (далее ОПС $)$ Оценивалось общее число словоупотреблений в области психичесих состояний, куда входили:

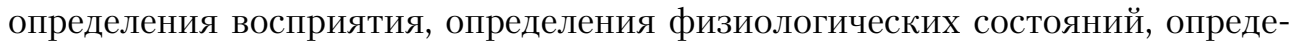

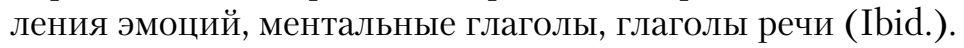

\section{Результаты}

Возрастная специфика в развитии модели психического и нарративньх способностей. При оценке возрастных различй между детьми 4 и 6 лет в понимании психичеких состояний достоверные значения по критерию Манна йн обнаружены по каждому из семи параметров, а также по общему пока вателю модели психичесого ( 的 с спосонстей: структура рассказа (U = 223.5 при $р$ < 0.000), описание психических состояний (U = 310.5 при р = 0.037), информативность сообщений ( $\mathrm{U}$ = 312 при $p=0.031$.

Содержательно возрастные различия в нарративной компетенции выража лись в следующем в 60\% нарративов в группе четырехлетних участиков содержалось только описание попытки персонажа и результата события, в группе шестлетних детей количество таких случаев сократилось до 13\%. Также жвеличилось количесто описаний, содержащих указание на цель персонажа, пго псиические состояния как начало события или реакцию. Количесто детей, чьи нарративы описывали информацию полностью с указанием ментальной причинности (т.е. с включением интерпретации события геpoeg, что разделяет уровни действия и сознания), возросло с 2 до $56 \%$ Процент ОПС ( ) частотным было употребление слов, определяющих эмоции персонажа, глаголов восприяти и ментальных глаголов.

Результаты корреляционного анализа между отдельными аспектами модепи психческого и нарративных способностей в разных возрастных группах демонстрируют изменения характера взаимосвязи. Так, в группе детей 4 лет обнаружены корреляции между пониманием неверного мнения и показателями структуры ( $r=0.409$, при $p=0.043)$ и информативности текста ( $r=0.475$, при $p=0.016)$, a также между пониманием ментальной причинности с OПС ( $r=0.366$, при $p=0.046)$ и информативностью ( $r=0.489$, при $p=0.006)$. В группе детей 6 лет связи обнаружены между пониманием живого и неживого со

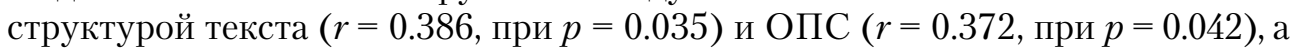
также пониманием неверного мнения и ОПС ( $r=0.388$, при $p=0.045)$.

Нарративнье способности при разном ировне модели психиеского. При сравнении групп детей с низким, средним и высоким уровнем развития модели психичесого с помощью критерия Краскела-Уоллиса мы получили значения, демонстрирующие достоверные различия выделенных нами характеристик нарративной компетенции: $\mathrm{H}=8.4(p=0.015)$ при оценке информативности 
Количество детей, описывающих психические состояния (в \%)

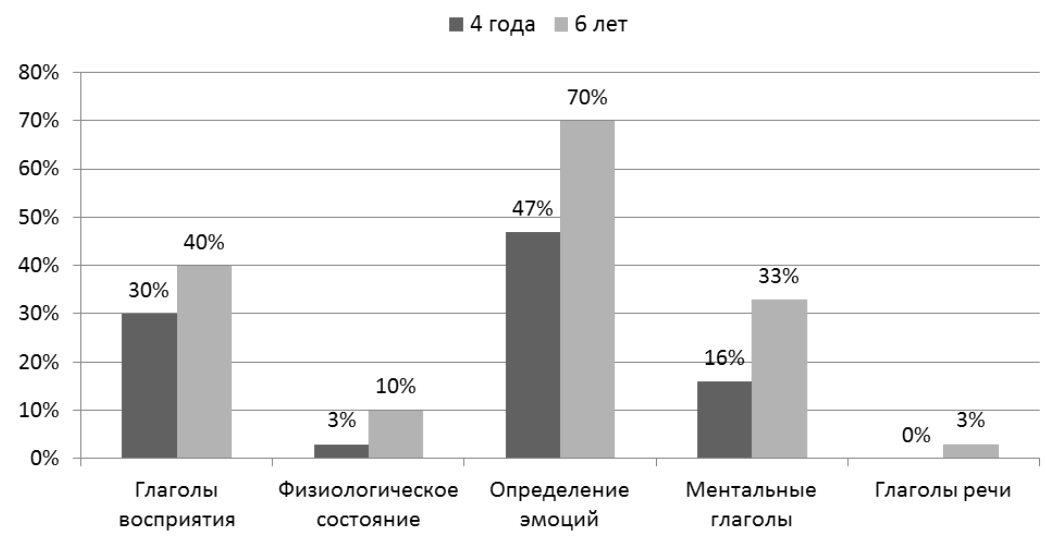

Рисунок 2

Средние значения показателей нарративных способностей у групп с низким, средним и высоким уровнем модели психического

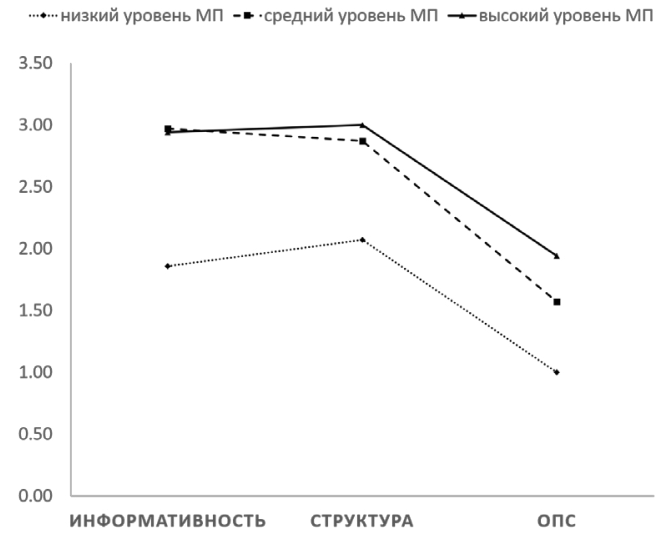

Примечание. МП - модель психического, ОПС - описание психических состояний.

пересказа, $\mathrm{H}=10(\mathrm{p}=0.006)$ при оценке структуры нарратива и $\mathrm{H}=5.6(p=0.060)$ при оценке употребления слов, описывающих психические состояния. Показатели средних значений трех экспериментальных групп сопоставимы у групп со средним и высоким уровнем модели психического и значительно отличались у группы детей с низким уровнем (рисунок 2).

Нарративы детей с низким уровнем модели психического характеризовались недостаточным или частичным уровнем информативности в 85\% случаев, были пропущены отдельные элементы сюжета, нарушена причинно-следственная связь событий. Более 70\% нарративов этой группы содержали указание только на попытку и результат события или один из этих элементов, не 
были описаны цель, время, место, реакция персонажа на происходящее. При анализе описаний психических состояний только в $36 \%$ случаев были зафиксированы определения эмоций, в 23\% - глаголы восприятия, в 14\% - ментальные глаголы.

В группе детей с высоким показателем модели психического процент нарративов с укороченной структурой (попытка+результат) сократился до $19 \%$. Информативность в $62 \%$ случаев была высокой (фактологически или с указанием ментальной причинности). 81\% нарративов содержал те или иные средства описания психических состояний.

При оценке сопряженности между показателями речевого развития по субтестам Векслера и моделью психического, а также нарративной компетенцией взаимосвязей обнаружено не было, что требует отдельного детального изучения.

\section{Обсуждение результатов}

Полученные данные об увеличении показателей модели психического в период 4-6 лет соответствует результатам современнхм исследований. Описанная возрастная специфика в области нарративной компетенции также поддерживает имеющиеся данные о том, что с момента появления нарративных навыков в 3-4 года нарративы детей становятся длиннее, чаще имеют законченную структуру, в них появляется больше эпизодов, описаний причинно-следственных связей, эмоций и мыслей персонажей (Ovchinnikova, 2005). Анализируя развитие отдельных характеристик нарративных способностей, стоит отметить, что структура текста как показатель наличия отдельных частей сюжета осваивается детьми несколько раньше, чем информативность - содержательная характеристика, предполагающая связность и целостность описания.

Полученные данные расширяют представления в области изучения нарративных способностей детей, методология оценки которых, как правило, построена на пересказе готового сюжета/текста. Методическое решение создания нарратива на основании инструкции с пропущенным эпизодом позволило анализировать тексты, обладающие большей долей продуктивности не только с точки зрения речевой деятельности, но и репрезентации ребенком сюжета. В результате были описаны элементы, отсутствующие в инструкции, но используемые детьми с разной частотой при пересказе (например, описания причинно-следственных связей, в том числе через указание психических состояний персонажа). Развернутость этих элементов, согласно полученным данным, сопряжена с более полным пониманием психических состояний, что, на наш взгляд, объясняется необходимостью координации своей точки зрения, коммуникативного партнера и героя истории.

Качественный анализ текстов показал, что определение эмоций персонажа встречается в нарративах чаще определения других психических состояний. Как характеристика нарратива количество слов, описывающих психические состояния, не только планомерно увеличивается с развитием модели психического, но 
и сохраняет к 6 годам связи с отдельными ее аспектами (неверные мнения, понимание живого и неживого), по-видимому, необходимыми для совершенствования этой области нарративной компетенции. Таким образом, полученные данные согласуются с выводами группы исследований, описывающих взаимосвязь между развитием модели психического и использованием ментального словаря (Symons et al., 2005; Meins et al., 2006; и др.), и дополняют результаты исследования Д. Саймонса с коллегами, которые выявили рост количества связей между моделью психического и дискурсом о психических состояниях с возрастом, но в группе 4-5 лет эта сопряженность представлена только задачей на понимание эмоций, вызванных неверным мнением (Symons et al., 2005). В нашей работе употребление слов, обозначающих психические состояния детьми 4 лет, демонстрирует связь с таким аспектом, как понимание ментальной причинности событий, который по сравнению с неверным мнением оценивает способность использовать каузальный принцип объяснения поведения героев. Описание причин действий агента требует использования ментального словаря; вероятно, данная обусловленность имеет особое значение в период, когда нарративные способности только начинают развиваться.

Параметры структуры и информативности текста также выявили достоверные различия и между возрастными группами, и между группами с различным уровнем понимания психических состояний. Как и в исследовании Т. Чарман и Я. Шмуэли-Гетц, не были обнаружены связи показателей сложности и структуры нарративов детей старшего дошкольного возраста с пониманием психического мира, однако, согласно нашим данным, эта связь выявляется у группы детей 4 лет (Charman, Shmueli-Goetz, 1998). Такой результат может свидетельствовать о большей роли модели психического для становления параметров нарративных способностей в возрасте около 4 лет. Кроме сопряженности с пониманием неверного мнения, информативность нарративов в младшей возрастной группе также связана с показателем понимания ментальной причинности событий. Можно предположить, что фокус данной методики на способности анализировать причины событий ментального плана обнаруживает ее значимость для развития целостности и связности повествования (как и в случае с параметром ОПС).

В целом при сравнении соотношения отдельных аспектов нарративных способностей и модели психического в двух возрастных группах было показано следующее: в 4 года каждая из нарративных компетенций обнаружила взаимосвязь с тем или иным показателем модели психического, в 6 лет наибольшую поддержку в отношении понимания психического мира обнаружил только показатель описания психических состояний. Данный результат, вопервых, отражает тенденцию ослабления связей модели психического с другими аспектами возрастного развития, описанную в литературе (Сергиенко и др., 2009), а, во-вторых, может свидетельствовать об опосредованном влиянии уровня развития языка, также претерпевающего существенные изменения в этот возрастной период. Для уточнения такого влияния необходим контроль этого фактора. 
Уровневый подход, примененный в исследовании, позволил описать интересную тенденцию: существенные различия в нарративах выявлены между группами детей с низким и средним уровнем понимания психических состояний. Уровень нарративной компетенции детей со средним и высоким уровнем модели психического имеет схожий характер. Данный результат может свидетельствовать о существовании пороговой связи, в соответствии с которой понимание психических состояний является необходимым, но недостаточным для становления нарративных способностей. Дети из группы с высоким развитием модели психического уже в четырехлетнем возрасте способны к описаниям событий с достаточно полной структурой нарратива и высокой информативностью, указанием психических состояний, что также дает основание рассматривать модель психического как когнитивный ресурс для конструирования нарратива. Следует отметить, что изучение отдельных аспектов речевого развития создает сложную картину взаимосвязей языка и модели психического, а вопрос о направленности влияния между ними остается дискуссионным (Astington, Baird, 2005). При этом построение нарративов рассматривается многими авторами как интегративная языковая способность, включенная в повседневные коммуникативные задачи ребенка и поэтому перспективная для изучения связи между языком и моделью психического (Tompkins et al., 2019).

Особенности нарративов детей из группы с низким развитием модели психического, полученные в нашем исследовании, схожи с результатами детей при различных нарушениях развития, описанных в литературе (Baixauli et al., 2016).

Учитывая взаимосвязь между моделью психического и уровнем развития речи, подтвержденную в большом количестве исследований, можно предположить, что в период между 4 и 6 годами достижение определенного уровня языкового развития сочетается с достаточным уровнем когнитивных способностей, что позволяет ребенку удерживать в сознании и успешно описывать события ментального плана.

\section{Литература}

Виленская, Г. А., Лебедева, Е. И. (2018). Модель психического и контроль поведения у детей дошкольного возраста с типичным развитием и нарушением речи. В кн. Психическое здоровье и образование: сборник научных статей по материалам II Конгресса «Психическое здоровье человека ХХІ века» (с. 258-262). М.: ИД «Городец».

Демидова, И. Г., Соколова, О. Л., Чирков, В. И. (1992). Тест «Нарисуй человека»: Руководство. Ярославль: ЯрГУ /НПЦ «Психодиагностика».

Лебедева, Е. И. (2006). Понимание ментального и физического мира детьми с типичным развитием и расстройствами аутистического спектра (Кандидатская диссертация). Государственный университет гуманитарных наук, Москва.

Сергиенко, Е. А., Лебедева, Е. И., Прусакова, О. А. (2009). Модель психического как основа понимания себя и другого в онтогенезе человека. М.: ИП РАН. 
Уланова, А. Ю., Сергиенко, Е. А. (2015). Развитие представлений о ментальном и физическом в пересказах детей дошкольного возраста. Современные проблемь науки и образования, 1. Режим доступа: http://www.science-education.ru/pdf/2015/1/528.pdf

Филимоненко, Ю. И., Тимофеев, В. И. (1994). Руководство к методике исследования интеллекта у детей Д. Векслера (WISC). СПб.: ГП «Иматон».

Ссылки на зарубежные источники см. в разделе References после англоязычного блока.

Уланова Анна Юрьевна - научный сотрудник, лаборатория психологии развития субъекта в нормальных и посттравматических состояниях, ФГБУН «Институт психологии Российской академии наук», кандидат психологических наук.

Сфера научных интересов: психология развития, понимание психического мира, модель психического, развитие социокогнитивных навыков, дошкольный возраст.

Контакты: ulanovaaj@ipran.ru

\title{
Narratives of Children with Different Levels of Understanding of Mental States
}

\author{
A.Yu. Ulanova \\ ${ }^{a}$ Institute of Psychology, Russian Academy of Sciences, 13 build. 1, Yaroslavskaya Str., Moscow, 129366, \\ Russian Federation
}

\begin{abstract}
The article presents the results of a study of various components of the narrative competence of 4 and 6-year-old children in the context of developing theory of mind - a system for representing knowledge about mental phenomena of other people. We consider a narrative not only as an important communication tool and integrative language ability, but also as a method for analyzing the understanding of mental states and events. The analysis of the structural and content characteristics of children's narratives in relation to theory of mind allows us to study the pragmatic aspects of communication, focus on a partner and the ability to take into account their point of view. The study involved 60 children who told stories to another child. The children's narratives were created according to the instructions so that the central part was missing. The narratives were evaluated according to the structure, informativity, quantity and specificity of descriptions of mental states. We evaluated theory of mind using a battery of tasks: understanding false beliefs, intentions, emotions, etc. The results showed a qualitative leap in the development of a theory of mind and narrative abilities from 4 to 6 years, as well as a change in the nature of the relationships between them in two age groups. Differences were found in all the studied characteristics of narratives in children with different levels of theory of mind: children who understand mental states better made more detailed, consistent descriptions, including an indication of causality and various mental states of the characters. The age specificity in the description of mental states is also shown. The data show that theory of mind can be viewed as one of the cognitive resources for constructing narrative.
\end{abstract}

Keywords: narrative abilities, understanding of the mental states, theory of mind, preschool age. 


\section{References}

Astington, J. W. (1990). Narrative and the child's theory of mind. In B. K. Britton \& A. D. Pellegrini (Eds.), Narrative thought and narrative language (pp. 151-171). Hillsdale, NJ: Erlbaum.

Astington, J. W., \& Baird, J. A. (2005). Why language matters for theory of mind. Oxford University Press.

Astington, J. W., \& Jenkins, J. M. (1999). A longitudinal study of the relation between language and theory-of-mind development. Developmental Psychology, 35(5), 1311-1320.

Baixauli, I., Colomer, C., Roselly, B., \& Miranda, A. (2016). Narratives of children with high-functioning autism spectum disorder: a meta-analysis. Research in Developmental Disabilities, 59, $234-254$.

Capps, L., Losh, M., \& Thurber, C. (2000). The frog ate the bug and made his mouth sao competence in children with autism. Journal of Abnormal Child Psychology, 28(2), 193-204.

Charman, T., \& Shmueli-Goetz, Y. (1998). The relationship between theory of mind, language and nar rative discourse: An experimental study. Cahiers de Psychologie Cognitive/Current Psychology of Cognition, $17(2), 255-271$

Demidova, I. G., Sokolova, O. L., \& Chirkov, V. I. (1) (Pes). Test Narisui cheloveka” [Draw a Person Test 1 .

Filimonenko, Yu. I., \& Timofeev, V. I. (1994). Rukovodstoo $k$ metodike issledovaniya intellekta u detei D. Vekslera (WISC) [Guidelines for the D. Wechsler Intelligence Scale for Children (WISC)]. Saint Petersurg: GP “Imaton” (in Russian)

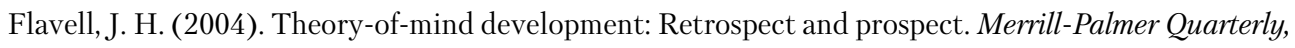
$50(3), 274-290$.

Gagarina, N., et al. (2012). MAIN: Multilingual Assessment Instrument for Narratives. ZAS Papers in Linguistics, $56,1-135$.

Gopnik, A., \& Astington, J. W. (1988). Children's understanding of representational change and its relation to the understanding of false belief and appearance-reality distinction. Child Development, 59, 26-37.

Lebedeva, E. I. (2006). Ponimanie mental'nogo i fizicheskogo mira det'mi s tipichnym razuitiem $i$ rasstroistrami autisticheskogo spektra [Understanding of the mental and physical world by children with the typical development and with autistic spectrum disorders] (PhD dissertation). State University for the Humanities, Moscow, Russian Federation. (in Russian)

Meins, E., Fernyhough, C., Johnson, F., \& Lidstone, J. (2006). Mind mindedness in children: Individual differences in internal state talk in middle childhood. British Journal of Developmental Psychology , 24(1), $181-196$.

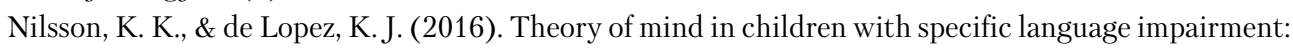
A systematic review and meta analysis. Child Development, $\mathbf{\text { or }}(1), 143-153$.

O'Neill, D. K., \& Shultis, R. M. (2007). The emergence of the ability to track a character's mental perspective in narrative. Development Psychology 43 (4), 1032 1037.

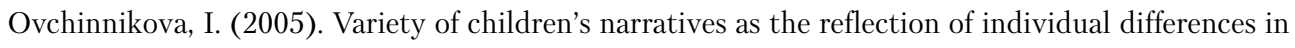

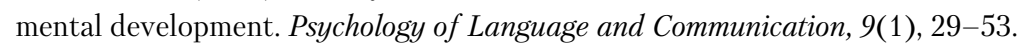

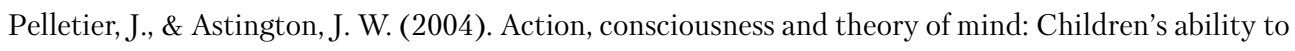

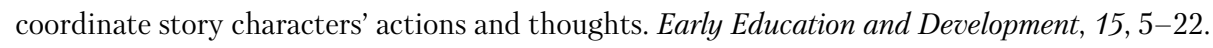

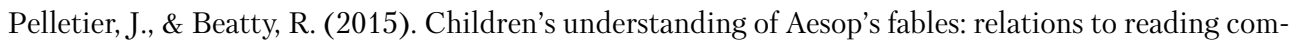

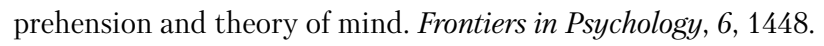

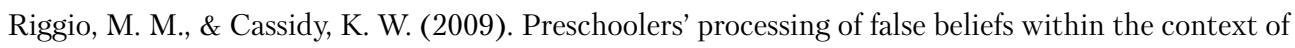

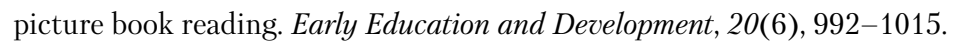


Sergienko, E. A., Lebedeva, E. I., \& Prusakova, O. A. (2009). Model' psikhicheskogo kak osnova ponimaniya sebya i drugogo $v$ ontogeneze cheloveka [Theory of mind as the basis for understanding oneself and the other in ontogenesis of a human]. Moscow: Institute of Psychology of the RAS. (in Russian)

Symons, D. K., Peterson, C. C., Slaughter, V., Roche, J., \& Doyle, E. (2005). Theory of mind and mental state discourse during book reading and story telling tasks. British Journal of Developmental Psychology, 23(1), 81-102.

Tompkins V., Farrar M. J., \& Montgomery D. E. (2019). Speaking your mind: language and narrative in young children's theory of mind development. Advances in Child Development and Behavior, 56, 109-140.

Ulanova, A. Yu., \& Sergienko, E. A. (2015). Representations of mental and physical in preschoolers retelling. Modern Problems of Science and Education, 1. Retrieved from http://www.science-education.ru/pdf/2015/1/528.pdf (in Russian)

Van den Broek, P., Lorch, E. P., \& Thurlow, R. (1996). Children's and adults' memory for television stories: The role of causal factors, story grammar categories, and hierarchical level. Child Development, 67(6), 3010-3028.

Vilenskaya, G. A., \& Lebedeva, E. I. (2018). Model' psikhicheskogo i kontrol' povedeniya u detei doshkol'nogo vozrasta s tipichnym razvitiem i narusheniem rechi [Theory of mind and behavioral control in preschool children with the typical development and with speech disorders]. In Psikhicheskoe zdorov'e i obrazovanie: sbornik nauchnykh statei po materialam II Kongressa "Psikhicheskoe zdorov'e cheloveka XXI veka" [Mental health and education: Proceedings of the II Congress "Mental Health of a 21-Century Person”] (pp. 258-262). Moscow: ID "Gorodets". (in Russian)

Wimmer, H., \& Perner, J. (1983). Beliefs about beliefs: representations and constraining functions of wrong beliefs in young children's understanding of deception. Cognition, 13, 103-128.

Anna Yu. Ulanova - Research Fellow, laboratory of developmental psychology of the subject in the normal and post-traumatic states, Institute of Psychology, Russian Academy of Sciences, $\mathrm{PhD}$ in Psychology.

Research Area: developmental psychology, understanding the mental world, theory of mind, socio-cognitive abilities, preschool age.

E-mail: ulanovaaj@ipran.ru 